\title{
The role of siblings in identity development in adolescence and emerging adulthood
}

\author{
Thessa M.L. Wong ${ }^{\mathrm{a}, *}$, Susan J.T. Branje ${ }^{\mathrm{b}, 1}$, Inge E. VanderValk ${ }^{\mathrm{b}, 2}$, Skyler T. Hawk ${ }^{\mathrm{b}, 3}$, \\ Wim H.J. Meeus ${ }^{\text {b, }}$
}

${ }^{a}$ Utrecht University, Research Centre Adolescent Development, Utrecht, The Netherlands

${ }^{\mathrm{b}}$ Utrecht University, Research Centre Adolescent Development, P.O. Box 80.140, 3508 TC Utrecht, The Netherlands

Keywords:

Siblings

Identification

Differentiation

Identity

\begin{abstract}
A B S T R A C T
This study examined the role of siblings on identity formation in adolescence and emerging adulthood, using a three-wave longitudinal design. Measures of identity formation were filled out by 498 sibling dyads. Sibling effects differed as a function of age and gender configuration within the dyads. Controlled for age, earlier-born siblings reported the most advanced levels of identity formation, and later-born siblings the lowest. Positive relations between siblings' identity and changes in identity of respondents provided support for modeling processes between siblings. The identity of earlier-born same-sex siblings, in particular, tends to be important in influencing identity formation. Contrary to the expectations, differentiation processes between siblings did not appear to influence identity formation. It is apparent from this study that both the gender and birth order of siblings affect whether their own identity formation processes influence those of adolescents and emerging adults.
\end{abstract}

(c) 2009 The Association for Professionals in Services for Adolescents. Published by Elsevier Ltd. All rights reserved.

The roles siblings play in psychological development has received increased attention in recent years (Brody, 1998). Identity formation is one aspect of development in which sibling influences may be particularly important (Erikson, 1968). According to Erikson, identity formation is an important developmental task in adolescence and emerging adulthood. It occurs within a framework of interpersonal experiences, many of which take place within the family context. Adolescence and emerging adulthood is typically the period in which identity formation is thought to occur (e.g., Arnett, 2000; Erikson, 1968; Waterman, 1988). The current study focuses on the effects that siblings can have upon this process, by examining identity implementation of adolescents and emerging adults in various types of sibling dyads, and the influence of siblings' identity on changes in respondents' identity.

\footnotetext{
* Corresponding author. VU University Amsterdam, Faculty of Law, Department of Criminal Law and Criminology, De Boelelaan 1105, 1081 HV Amsterdam, The Netherlands. Tel.: +31 20598666; fax: +31 205986230.

E-mail addresses: t.wong@rechten.vu.nl (T.M.L. Wong), s.branje@uu.nl (S.J.T. Branje), i.e.vandervalk@uu.nl (I.E. VanderValk), s.t.hawk@uu.nl (S.T. Hawk), w.meeus@uu.nl (W.H.J. Meeus).

1 Tel.: +31 30 2534039; fax: +31302537731.

2 Tel.: +31 30 2534703; fax: +3130 2537731 .

3 Tel.: +31 30 2535844; fax: +31 302537731 .

4 Tel.: +31 30 2534890; fax: +31 302537731 .
} 


\section{Identity}

Marcia (1966) introduced the conceptual and methodological ground for studying Erikson's (1968) theory on identity formation. In his model, Marcia examined identity in terms of two dimensions, namely exploration and commitment. Exploration involves questioning and comparing different identity alternatives. Commitment, in contrast, refers to a person showing investment in one or more of these alternatives. A different classification approach calls attention to the continuous evaluation and reformulation of identity commitments (Bosma \& Kunnen, 2001; Crocetti, Rubini, \& Meeus, 2008; Kerpelman, Pittman, \& Lamke, 1997; Luyckx, Goossens, Soenens, \& Beyers, 2006; Meeus, 1996). Meeus (1996) modified Marcia's model by further dividing his concept of exploration into two categories, namely in-breadth exploration versus in-depth exploration. The latter term refers to dealing with commitments in an active manner. The difference between the two types of exploring is that, whereas Marcia's original concept of in-breadth exploration precedes and facilitates the formation of commitments, indepth exploration represents the extent to which adolescents actively explore the commitments that they have already made. In-depth exploration is a process of continuously monitoring present commitments, by reflecting on one's choices, searching for information about these commitments, and discussing them with others. This serves the functions of helping individuals to consciously consider and maintain their commitments. Thus, exploration in breadth is part of the process of selecting identity commitments, whereas in-depth exploration is part of the process of maintaining identity commitments. In-depth exploration indicates whether or not adolescents actively consider both positive and negative aspects of their present commitments. Adolescents with a high level of in-depth exploration actively maintain their commitments by constantly considering them. Conversely, those with a low level routinely maintain their prior choices by simply remaining committed, without further consideration. A detailed discussion on the differences between identity dimensions can be found in Crocetti, Rubini, \& Meeus, (2008). As the interest of this study is to examine implementation of identity, we examine in-depth exploration, rather than exploration in breadth. For the sake of simplicity, we use the term 'exploration' in this paper as a reference to in-depth exploration.

\section{Sibling processes}

Identity development is related to psychological adjustment (Meeus, Iedema, Helsen, \& Vollebergh, 1999). For instance, people with a slow identity development (i.e., people who have not yet reached an achieved identity in emerging adulthood) are found to score low on psychological well being (Meeus et al., 1999). For such reasons, it is critical for researchers to obtain extensive knowledge of processes that affect identity development.

Erikson (1968) posited that, within the family, several factors could affect identity development. For example, adolescents from supportive and nurturing families appear to display higher levels of commitment and exploration (Luyckx et al., 2006). Additionally, Grotevant and Cooper's (1985) examination of two-parent families showed that interaction patterns between family members influence adolescents' levels of exploration (in breadth), but also that these influences differ between mothers and fathers. While many studies have examined parental effects (Grotevant \& Cooper, 1985; Luyckx et al., 2006; Meeus, Oosterwegel, \& Vollebergh, 2002), the influences of other family members, such as siblings, have been given less attention. One recent study on this topic (Deković \& Buist, 2005) recently examined 11-16year-old sibling dyads. This cross-sectional investigation found that sibling relationship quality was positively related to the level of exploration in the relational domain. A subsequent review of the literature pertaining to sibling influences on identity formation did not reveal any studies in which a longitudinal design was employed. By using three waves of data from the longitudinal Utrecht Study of Adolescent Development (USAD), the current research can contribute to the limited knowledge on the role of siblings in identity formation by investigating whether sibling characteristics (specifically birth order and gender) and sibling identity functioning (specifically identity exploration and commitment) have impacts upon identity change over time.

Siblings may influence each other's identities through two potential processes. In the first process, sibling identification, people learn new behaviors by interacting with the sibling and observing and imitating his or her behavior (Bank \& Kahn, 1976). The opposite process is sibling differentiation, in which adolescents and emerging adults try to distinguish themselves from one another by emphasizing their uniqueness (Sulloway, 1996). Whether and how these processes take place may depend on factors that significantly affect the interaction patterns between siblings, such as gender constellation and birth order. Gender constellation is important in identification and differentiation processes, with same-sex siblings being more influential in identification than opposite-sex siblings (Benin \& Johnson, 1984). Likewise, differentiation was found to be higher in same-sex siblings compared to opposite-sex siblings (Schachter, Gilutz, Shore, \& Adler, 1978). With regard to birth order, prior research has shown that later-born siblings are more likely to identify with their earlier-born sibling's behavior than the reverse, perhaps because earlier-born siblings are higher in status (Branje, Van Lieshout, Van Aken, \& Haselager, 2004; Whiteman, McHale, \& Crouter, 2007). The influence of identification processes appears to become stronger with increased age difference between siblings (French, 1984). Differentiation processes, on the other hand, are mostly observed among people who have younger siblings (Branje et al., 2004; Whiteman et al., 2007). As developing one's own identity becomes increasingly important in adolescence, influences of differentiation may become stronger for earlier-born siblings as they age (Feinberg, McHale, Crouter, \& Cumsille, 2003).

These birth order influences were recently demonstrated in a study on gender identity development, in which earlier-born siblings were indeed found to differentiate from their later-born siblings, whereas later-born siblings identified with their 
older-siblings (McHale, Updegraff, Helms-Erikson, \& Crouter, 2001). In addition, siblings close in age (with an age difference less than 2 years) are likely to differentiate from each other (Feinberg \& Hetherington, 2000), probably because their age similarity leads to a desire for more uniqueness. Siblings who differ more greatly in age are already quite different, so there is less pressure to call attention to their dissimilarities. In sum, differentiation appears to typically be the predominant process for both people with a younger sibling and people with a sibling close in age. The motives for differentiation are not the same for these two groups, however. Adolescents and young adults with a sibling close in age seek to enhance existing differences, as belonging to the same age cohort likely already produces greater similarity. Adolescents and emerging adults with a younger sibling, however, want to differentiate because they are older and their desire to be unique is bigger than for younger siblings (Branje et al., 2004).

Apart from the sibling processes involved, we expect birth order to influence identity in terms of mean differences. Earlierborn siblings have more authority and adult-like responsibility, as compared to their later-born siblings (Buhrmester \& Furman, 1990; Furman \& Buhrmester, 1985). Adler (1928) also highlighted characteristics of first-borns that distinguish them from later-born children, such as the fact that first-borns experience the trauma of losing undivided parental attention when another sibling is born, and therefore first-borns might imitate their parents to a greater extent than later-born offspring. Additionally, first-borns typically display more conscientiousness than later-born children (Plotkin, 1999; Sulloway, 2001). These characteristics of first-borns indicate that they usually behave in a more mature way than later-borns. This is probably the case for earlier-born siblings as well, since they may be first-borns and later-born siblings are not first-borns by definition. Applying these birth order issues to the topic of identity formation, earlier-born siblings might show higher levels of commitment and exploration than later-born siblings, because high levels of commitment and exploration are an indication of maturity (Kalakoski \& Nurmi, 1998).

In terms of identity development, we expect identification and differentiation to influence one's exploration of identity alternatives more strongly than one's actual commitment to those choices. This is because commitment is a more intrinsic, and thus less visible, type of behavior than exploration. It is therefore likely that siblings are less aware of each others' commitments than they are of each others' exploration behaviors. Research on other types of visible behavior, such as smoking or sexual activity, have confirmed this modeling of siblings' behavior (Bard \& Rodgers, 2003; Rodgers, Rowe, \& Harris, 1992). Studies on intrinsic characteristics, such as emotional development and sibling influence (e.g., Bedford \& Volling, 2004), have more often focused upon effects of sibling relationship quality than upon modeling of siblings' behaviors.

\section{Research questions}

The current study utilizes three annual waves of data to examine whether siblings influence adolescents' and emerging adults' identity formation in the domains of school and work. Identity in these domains refers to whether people are committed to, and actively explore, their choices regarding school and work. Research has shown that siblings, especially older ones, can have important influences upon school and career choices of other children in the family (Schultheiss, Palma, Predragovich, \& Glasscock, 2002; Whiston \& Keller, 2004).

Our first research question is: Do earlier-born respondents (i.e., those with a sibling more than two years younger), respondents with a sibling close in age (i.e., those with a sibling within two years of age), and later-born respondents (i.e., those with a sibling more than two years older) differ in their mean levels of commitment and/or exploration? Since greater maturity levels are typically associated with being an earlier-born child, we expect higher levels of commitment and exploration for earlier-born respondents, as compared to later-born respondents or respondents with a sibling close in age.

The second question is: Is a sibling's commitment or exploration related to a respondent's concurrent commitment or exploration within each of the three measurement waves, as well as over time? Moreover: Does birth order affect these sibling influences? In accordance with sibling identification processes, we hypothesize that (change) of later-born respondents' identity will be positively related to their sibling's identity. Specifically, we expect that later-born respondents will become more similar to their older sibling, in terms of their reported commitment and exploration, from Wave 1 to Wave 2 , and again from Wave 2 to Wave 3. In line with differentiation processes, we expect (change in) identity of siblings who are closer in age, and of earlier-born respondents, to be negatively related to their sibling's identity.

Thirdly: Are any of the findings for questions 1 and 2 affected by gender constellation? We expect no differences in mean levels between individuals with a same-sex sibling and individuals with an opposite-sex sibling. We do hypothesize stronger sibling influences for same-sex dyads than for opposite-sex dyads, however. Finally, we also examine whether the findings for question 1 and 2 differ for commitment and exploration. Since exploration is more visible for siblings, we expect sibling influences to be stronger regarding exploration, as compared to commitment.

\section{Method}

\section{Participants}

The sample contained 498 sibling dyads who were divided into six groups: 51 respondents with a same-sex sibling close in age (with an age difference of less than 2 years), 77 respondents with an opposite-sex sibling close in age, 98 earlier-born respondents with a same-sex sibling, 96 earlier-born respondents with an opposite-sex sibling, 88 later-born respondents with a same-sex sibling, and 88 later-born respondents with an opposite-sex sibling. At the first wave, 57 sibling dyads (11.4\%) 
came from non-intact families (i.e., parental divorce or death). During the study, parental divorce or death occurred in an additional 24 sibling dyads.

The sample consisted of 221 (44.4\%) males and 277 (55.6\%) females. The age range in the first wave was between 12 and 24 years. Table 1 displays the mean ages and genders of the participants, per sibling group. The six groups differed significantly in age $(F(5)=23.27, p<0.01)$, but not in gender $\left(\chi^{2}(5)=1.75, p=0.88\right)$. Just under half of participants lived apart from their parents ( $n=242 ; 48.6 \%), 191$ of whom moved away from home during the study. In Wave $1,82.5 \%$ of the respondents were currently in secondary school or university. This proportion decreased in Wave 2 (67.7\%), and again in Wave 3 (44.6\%).

This sample was a sub-sample of the three wave longitudinal study 'Utrecht Study of Adolescent Development (USAD)' (Meeus \& 't Hart, 1993). The first measurement was in 1991, the second in 1994, and the third in 1997. The sample included only native Dutch adolescents and emerging adults, and is considered to be representative of this population in the early 1990s ('t Hart, 1992, as described in Meeus, Iedema, \& Maassen, 2002; Meeus, Oosterwegel, et al., 2002). For this study, 3354 adolescents and emerging adults participated in at least one of the waves. A random selection of 1302 respondents was followed longitudinally, with the other respondents participating only once. The participants were interviewed at home and asked to fill out questionnaires in the presence of the interviewer. They also received another questionnaire to complete on their own and send back to the research organization via mail. Confidentiality was guaranteed. The current study used data of both longitudinal and non-longitudinal respondents from the second questionnaire.

The sibling sample was selected by deleting the families from which only one respondent participated. Of families in which more than two adolescents or emerging adults participated, two offspring were selected at random. It should be kept in mind that, although sibling dyads are analyzed, other siblings may also be present in the family.

\section{Measures}

Identity

Identity was measured with the Utrecht-Groningen Identity Development Scale (U-GIDS, Meeus \& 't Hart, 1993), which is based on Bosma's (1985) GIDS. It was assessed by measuring commitment and exploration in the domains of school and work.

\section{Commitment}

Commitment refers to strong investments made concerning school and work, and the self-confidence adolescents derive from these investments. There were eight five-point Likert items for the assessment of commitment $(1=$ completely untrue; 5 = completely true). Examples of items are "I am satisfied with my school/work" and "My school/work gives me security for the future." The scale is computed by taking the means of the item scores. Cronbach's alphas of the scale were between 0.80 and 0.89 across the three waves.

\section{Exploration}

Exploration represents the extent to which adolescents actively explore current commitments, by reflecting on their choices, looking for information, and discussing them with others. There were six five-point Likert items to assess exploration ( 1 = completely untrue; 5 = completely true). Examples of items are "I often talk about my school/work with other people" and "I put a lot of effort in exploring new things about my school/work". The scale was constructed by taking the means of the item scores. Cronbach's alphas of the scale were between 0.81 and 0.84 across the three measurement points.

\section{Results}

\section{Analytic strategy}

We used structural equation modeling in Mplus (Muthén \& Muthén, 1998) to examine the research questions. We performed six-group path analyses ${ }^{5}$ separately for commitment and exploration, in order to compare the different sibling groups. Regression paths were drawn between 'respondents' identity and the identity of their siblings, thereby controlling for stability in commitment and exploration in each wave, as well as concurrent correlations. Since respondents and siblings could belong to the same sibling type (for instance, an earlier-born sibling may be similar to an earlier-born respondent), means and paths of those belonging to the same sibling type were kept equal in all models. We compared the six sibling groups by evaluating a restricted model in which all the means and variances and the paths were held equal across groups (M1) against a model in which the means and variances were released (M2). The best-fitting model was compared with a model in which the stability paths were allowed to differ across groups (M3). The next model allowed concurrent correlations to be different among the groups (M4). The last models released the cross-paths between respondents and siblings, separately by sibling type. First, the cross-paths of earlier- or later-born respondents with a same-sex sibling were released (M5), then the cross-paths of earlier- or later-born respondents with an opposite-sex sibling (M6), next the cross-paths of

\footnotetext{
5 We performed additional analyses in order to explore the effects of gender and gender-sequencing in the sibling groups (e.g., same-sex male dyads, same-sex female dyads, opposite-sex dyads in which males are oldest, and opposite-sex dyads in which females are oldest). No significant effects of gender or gender-sequencing were found. It should be noted, however, that some of the subgroups in these analyses were quite small, resulting in limited power.
} 
Table 1

Age and sex per sibling group

\begin{tabular}{|c|c|c|c|c|}
\hline \multirow[t]{2}{*}{ Sibling group } & \multicolumn{2}{|l|}{ Age } & \multicolumn{2}{|c|}{ Gender $(n)$} \\
\hline & $M$ & SD & Male & Female \\
\hline All respondents $(N=498)$ & 16.33 & 3.35 & 221 & 277 \\
\hline Respondents with a same-sex sibling close in age $(n=51)$ & $16.86 \mathrm{a}$ & 2.97 & 23 & 28 \\
\hline Respondents with a opposite-sex sibling close in age $(n=77)$ & $18.81_{b}$ & 3.85 & 36 & 41 \\
\hline Later-born respondents with a same-sex sibling $(n=98)$ & $16.71_{\mathrm{a}}$ & 3.18 & 45 & 53 \\
\hline Later-born respondents with a opposite-sex sibling $(n=96)$ & $16.85_{\mathrm{a}}$ & 3.33 & 45 & 51 \\
\hline Earlier-born respondents with a same-sex sibling $(n=88)$ & $14.17_{\mathrm{c}}$ & 2.17 & 34 & 54 \\
\hline Earlier-born respondents with a opposite-sex sibling $(n=88)$ & $14.69_{\mathrm{c}}$ & 2.41 & 38 & 50 \\
\hline
\end{tabular}

Note. The six groups differed significantly in age $(F(5)=23.27, p<0.01)$. Means that do not share the same subscripts differ significantly from each other (at $p<0.05$. Means that share the same subscripts differ significantly from each other at $p<.05$.

respondents with a same-sex sibling close in age (M7), and finally the cross-paths of respondents with an opposite-sex sibling close in age (M8). Identification with a sibling would be indicated by a positive relation between respondents' and siblings' identity. A negative relation would be a sign of differentiation.

Goodness of fit of the models was evaluated through goodness of fit indicators and theoretical soundness. The comparative fit index (CFI. > 0.90 to indicate an acceptable fit) and the root-mean-square error of approximation (RMSEA; acceptable fit at $<0.08$ ) were used as goodness of fit indicators (Kline, 2005). To compare different models, we used the chi-square difference test. Since the models were estimated using MLR, for reasons of non-normally distributed variables (Satorra \& Bentler, 2001), the chi-square was corrected with the scaling correction factor before comparing two models. The Aikaike information criterion (AIC) also served as a model comparison index; the smaller the value, the better the model (Kline).

We controlled for age in all of the analyses, because of age differences between selected and non-selected participants and between the six groups of respondents. Moreover, prior studies have found age to be associated with identity development (Meeus, Van de Schoot, Keijsers, Schwartz, \& Branje, 2010). We also controlled for living status (living in parents' house or not), because there were differences in the distribution of this variable between the groups, and because it might have an impact on identity. We only controlled for living status at Waves 2 and 3, however, because all participants lived in their parents' home in two of the groups at Wave 1. By controlling for age and living status, we consider differences found in mean levels of commitment and exploration to be the result of the type of sibling one has.

\section{Preliminary analyses}

Because we selected a sub-sample from the main sample of longitudinal participants, we conducted some preliminary analyses to examine whether the selected and non-selected sample differed in meaningful ways. Selected respondents differed in age $(t(2288.18)=6.354, p<0.001)$, but not in gender $\left(\chi^{2}(3941)=1490.26, p>0.05\right)$, compared to non-selected respondents. Participants in the sample were somewhat younger than those non-selected $(\Delta M=0.96, \Delta \mathrm{SE}=0.15)$. Age significantly correlated with exploration in all of the waves ( $r$ wave $1=0.20$; rwave $2=0.27$; $r$ wave $3=0.19$ ), but not with commitment. Regarding identity, selected and non-selected respondents did not differ in levels of commitment, but they did differ in exploration in Wave $1(F(1)=6.292, p=0.01)$ and Wave $2(F(1)=14.031, p<0.001)$. In both waves, selected respondents scored lower on exploration than those who were not selected (respectively $\Delta M=0.10, \Delta S E=0.05 ; \Delta M=0.13$, $\Delta \mathrm{SE}=0.06)$.

\section{Descriptive statistics}

The means and standard deviations of commitment and exploration for all respondents, as well as per sibling group, are shown in Table 2.

\section{Commitment}

Model selection

For commitment, M2, which allowed means and variances to be free, had a significantly better fit than the fully restricted model (M1). Allowing stability paths and correlations to differ across groups did not improve model fit. The best-fitting model was M5, in which the means and variances were set free, as were the cross-paths between siblings' commitment and that of earlier- or later-born respondents with same-sex siblings. Freeing cross-paths of other respondents did not further improve model fit. Table 3 shows the fit indices for the tested models, and Fig. 1 shows the final model of the significant paths of commitment. For reasons of presentation, we present one figure in which the six groups are nested. The explained variances of the variables ranged from small (between 0.07 and 0.12 ) to moderate (between 0.17 and 0.22 ). 
Table 2

Mean scores of exploration and commitment per wave.

\begin{tabular}{|c|c|c|c|c|c|c|c|c|c|c|c|c|}
\hline \multirow[b]{3}{*}{ Sibling group } & \multicolumn{6}{|c|}{ Commitment } & \multicolumn{6}{|c|}{ Exploration } \\
\hline & \multicolumn{2}{|l|}{ W1 } & \multicolumn{2}{|l|}{ W2 } & \multicolumn{2}{|l|}{ W3 } & \multicolumn{2}{|l|}{ W1 } & \multicolumn{2}{|l|}{ W2 } & \multicolumn{2}{|l|}{ W3 } \\
\hline & $M$ & SD & $M$ & SD & $M$ & SD & $M$ & SD & $M$ & SD & $M$ & SD \\
\hline All respondents $(N=498)$ & 3.60 & 0.61 & 3.60 & 0.58 & 3.62 & 0.47 & 3.11 & 0.74 & 3.21 & 0.68 & 3.37 & 0.67 \\
\hline $\begin{array}{l}\text { Respondents with a same-sex } \\
\text { sibling close in age }(n=51)\end{array}$ & 3.72 & 0.62 & 3.69 & 0.59 & 3.66 & 0.60 & 3.21 & 0.83 & 3.37 & 0.68 & 3.44 & 0.68 \\
\hline $\begin{array}{l}\text { Respondents with a opposite-sex } \\
\text { sibling close in age }(n=77)\end{array}$ & 3.52 & 0.66 & 3.52 & 0.62 & 3.67 & 0.56 & 3.15 & 0.73 & 3.15 & 0.71 & 3.36 & 0.68 \\
\hline $\begin{array}{l}\text { Later-born respondents with } \\
\quad \text { a same-sex sibling }(n=98)\end{array}$ & 3.76 & 0.53 & 3.64 & 0.54 & 3.66 & 0.53 & 3.26 & 0.71 & 3.27 & 0.59 & 3.41 & 0.58 \\
\hline $\begin{array}{l}\text { Later-born respondents with a } \\
\quad \text { opposite-sex sibling }(n=96)\end{array}$ & 3.45 & 0.75 & 3.55 & 0.72 & 3.60 & 0.55 & 3.07 & 0.72 & 3.37 & 0.56 & 3.36 & 0.71 \\
\hline $\begin{array}{l}\text { Earlier-born respondents with } \\
\quad \text { a same-sex sibling }(n=88)\end{array}$ & 3.58 & 0.57 & 3.61 & 0.47 & 3.60 & 0.69 & 3.05 & 0.72 & 3.07 & 0.78 & 3.30 & 0.69 \\
\hline $\begin{array}{l}\text { Earlier-born respondents with a } \\
\quad \text { opposite-sex sibling }(n=88)\end{array}$ & 3.59 & 0.49 & 3.60 & 0.53 & 3.56 & 0.60 & 2.98 & 0.74 & 3.05 & 0.72 & 3.35 & 0.67 \\
\hline
\end{tabular}

Mean levels by sibling group

In terms of the estimated means, earlier-born respondents with a same-sex sibling had the highest initial level of commitment $(M=3.72, \mathrm{SD}=0.40)$, followed by respondents with a same-sex sibling close in age $(M=3.68, \mathrm{SD}=0.54)$, and earlier-born respondents with an opposite-sex sibling $(M=3.61, \mathrm{SD}=0.51)$. Later-born respondents with a same-sex sibling and respondents with an opposite-sex sibling close in age showed slightly higher levels of commitment (respectively $M=3.59 \mathrm{SD}=0.44$ and $M=3.58, \mathrm{SD}=0.49$ ). Later-born respondents with an opposite-sex sibling reported the lowest level of commitment $(M=3.56, \mathrm{SD}=0.38)$.

The influence of siblings' commitment

Looking more explicitly at the paths of commitment (see Fig. 1), we see that the stability paths of respondents' and siblings' commitment were positive and significant. This means that the rank order of commitment was relatively stable over time. Furthermore, commitment at Wave 3 was positively predicted by siblings' commitment at Wave 2 for later-born respondents with a same-sex sibling. There were no significant cross-paths, for any group, between siblings' commitment at Wave 1 and respondents' commitment at Wave 2. Additionally, we found no concurrent correlations between respondents' and siblings' commitment in any of the three measurement waves. Paths that were not significant for any group are omitted in Fig. 1.

\section{Exploration}

\section{Model selection}

Analyzing siblings' influence on exploration, we again found that M2 provided a better fit for the data than did M1. Releasing stability paths and correlations across groups did not further improve model fit. The model with the best fit was again M5 (see Table 3 and Fig. 2). Allowing cross-paths of other respondents to differ across groups did not further improve model fit. The explained variances again ranged from small (between 0.10 and 0.12 ) to moderate (between 0.13 and 0.23 ).

\section{Mean levels by sibling group}

In terms of the estimated means, earlier-born respondents with a same-sex sibling reported the highest initial level of exploration $(M=3.23, \mathrm{SD}=0.54)$, followed by earlier-born respondents with an opposite-sex sibling $(M=3.19, \mathrm{SD}=0.54)$,

Table 3

Fit Indices for nested models.

\begin{tabular}{|c|c|c|c|c|c|c|c|c|c|c|c|c|}
\hline \multirow[b]{2}{*}{ Model } & \multicolumn{6}{|c|}{ Commitment } & \multicolumn{6}{|c|}{ Exploration } \\
\hline & $\chi^{2}$ & $\mathrm{~d} f$ & CFI & RMSEA & $A I C$ & $\Delta \chi^{2}$ & $\chi^{2}$ & $\mathrm{~d} f$ & CFI & RMSEA & AIC & $\Delta \chi^{2}$ \\
\hline M1 & 282.89 & 208 & 0.92 & 0.07 & 8402.84 & & 352.17 & 208 & 0.86 & 0.09 & 9327.61 & \\
\hline M2 & 227.84 & 178 & 0.95 & 0.06 & 8394.62 & $51.81^{*}$ & 288,58 & 178 & 0.90 & 0.09 & 9321.99 & $62.90^{*}$ \\
\hline M3 & 214.42 & 163 & 0.95 & 0.06 & 8407.73 & 14.34 & 281,29 & 163 & 0.89 & 0.09 & 9341.03 & 9.62 \\
\hline M4 & 219.57 & 169 & 0.95 & 0.06 & 8404.51 & 8.21 & 279.66 & 169 & 0.90 & 0.09 & 9331.21 & 8.93 \\
\hline M5 & 217.59 & 174 & 0.95 & 0.06 & 8391.91 & $9.84^{*}$ & 277.95 & 174 & 0.90 & 0.08 & 9319.15 & $10.56^{*}$ \\
\hline M6 & 215.90 & 170 & 0.95 & 0.06 & 8398.12 & 1.89 & 272.95 & 170 & 0.90 & 0.09 & 9321.55 & 5.16 \\
\hline M7 & 217.36 & 172 & 0.95 & 0.06 & 8395.44 & 0.41 & 276.00 & 172 & 0.90 & 0.09 & 9321.80 & 1.68 \\
\hline M8 & 217.41 & 172 & 0.95 & 0.06 & 8395.75 & 0.19 & 277.20 & 172 & 0.90 & 0.09 & 9322.23 & 0.95 \\
\hline
\end{tabular}

Note. $C F I=$ Comparative Fit Index; RMSEA = Root Mean Square Error of Approximation. $\Delta \chi^{2}$ indicates the difference between the $\chi^{2}$, corrected by the scaling factor, of the model with that of the best previous model.

${ }^{*} p<0.05$. 


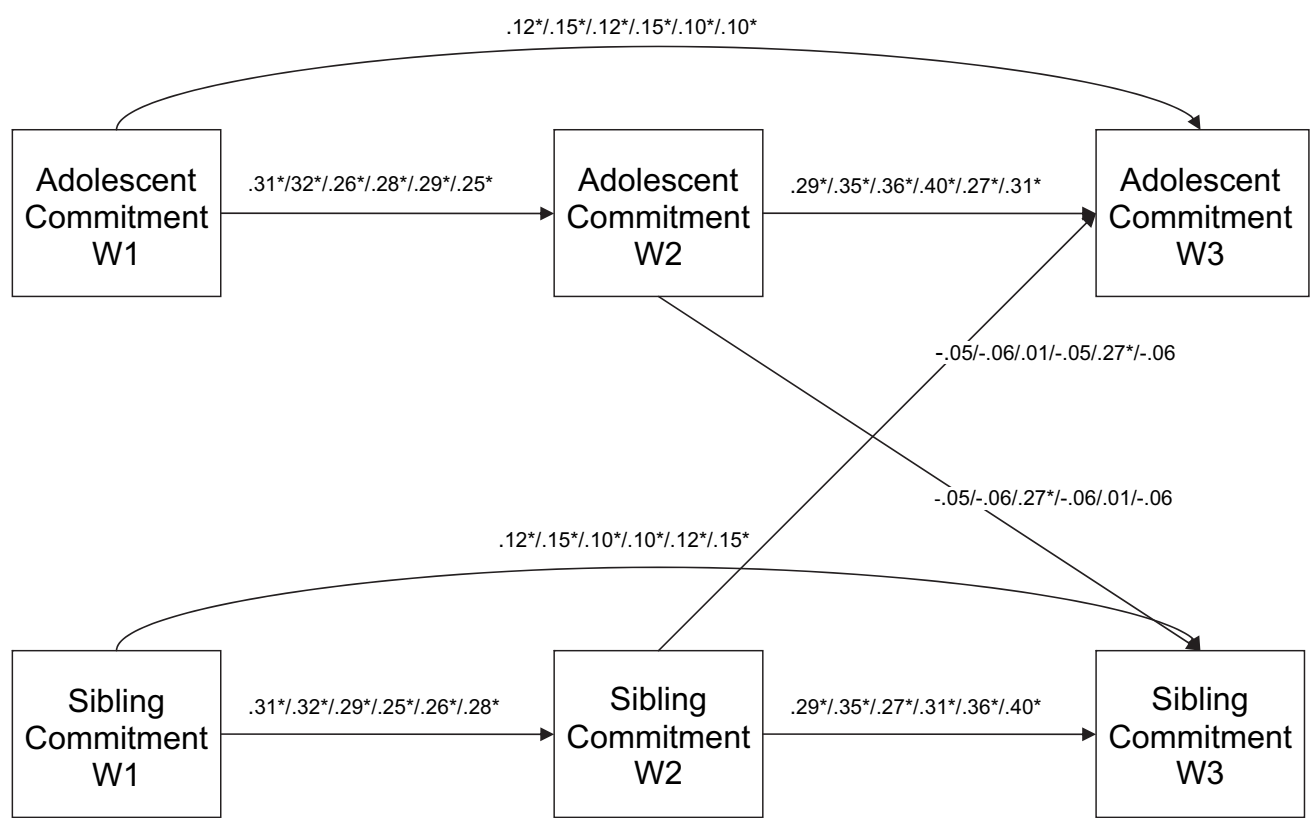

Fig. 1. Path-analytic model of sibling related commitment. Note. Standardized correlations of significant paths of the sibling groups are printed. The first two correlations are that of respectively respondents with a same-sex or with a opposite-sex sibling close in age, the third and fourth that of respectively earlier-born respondents with a same-sex or opposite-sex sibling, and the last two correlations that of respectively later-born respondents with a same-sex or opposite-sex sibling. Since paths of adolescents and siblings belonging to the same sibling type are set equal (for instance, a same-sex earlier-born sibling and a same-sex earlier-born respondent), coefficients of those adolescents are the same. For example, the third coefficient of adolescent commitment w2 $\rightarrow$ sibling commitment $\mathrm{w} 3$ is the same as the fifth coefficient of sibling commitment $\mathrm{w} 2 \rightarrow$ adolescent commitment $\mathrm{w} 3 .{ }^{*} p<0.05$.

and then respondents with an opposite-sex and same-sex siblings close in age (respectively $M=3.17, \mathrm{SD}=0.55$ and $M=3.15$, $\mathrm{SD}=0.56$ ). Later-born respondents with same-sex and opposite-sex siblings displayed the lowest initial levels of exploration (respectively $M=3.02, \mathrm{SD}=0.56$ and $M=2.96, \mathrm{SD}=0.55$ ).

\section{The influence of siblings' exploration}

All stability paths of exploration were significant (see Fig. 2). Siblings' exploration at Wave 1 positively predicted exploration at Wave 2 for all respondents, except earlier-borns with a same-sex sibling. Additionally, siblings' exploration at wave 2 positively predicted exploration at wave 3 for later-born respondents with a same-sex sibling, but not for the other respondents. In all three waves, and for all groups. The concurrent correlations between respondents' and siblings' exploration were not significant. Non-significant paths are omitted in Fig. 2.

In sum, earlier-born individuals showed higher levels of commitment and exploration than did later-borns. In terms of sibling influences, we found identification processes between siblings, but no differentiation processes. Same-sex siblings' levels of commitment and exploration positively affected these processes for later-born adolescents and emerging adults. Opposite-sex siblings affected respondents' levels of exploration, but not commitment, and this influence occurred regardless of whether respondents were earlier-born, later-born, or close in age to their sibling.

\section{Discussion}

The goal of this study was to examine whether siblings influence identity formation processes in adolescents and emerging adults. This longitudinal study confirms that siblings' own identity formation processes do indeed influence mean levels and changes in identity among adolescents and emerging adults.

Confirming our first hypothesis, we found that levels of commitment and exploration differed between people with differing sibling statuses. The highest levels of commitment and exploration were shown by earlier-born individuals, followed by those with a sibling close in age, and finally later-borns. In line with previous studies in which high levels of maturity were found in earlier-born siblings (Buhrmester \& Furman, 1990; Sulloway, 2001), the current study found more mature identity formation behaviors among earlier-born respondents. Earlier-born siblings are probably more mature than their later-born siblings, because they have higher responsibility levels (Buhrmester \& Furman, 1990; Furman \& Buhrmester, 1985) and because they feel the need to imitate their parents' (mature) behavior (Adler, 1928).

In agreement with our expectations, we found effects of siblings' identity on respondents' own identity, although only in terms of identification processes. Furthermore, we found significant sibling effects over time, but no evidence was found for concurrent sibling influences. This may indicate that sibling are not apparent in the short-term, but instead emerge over time. 


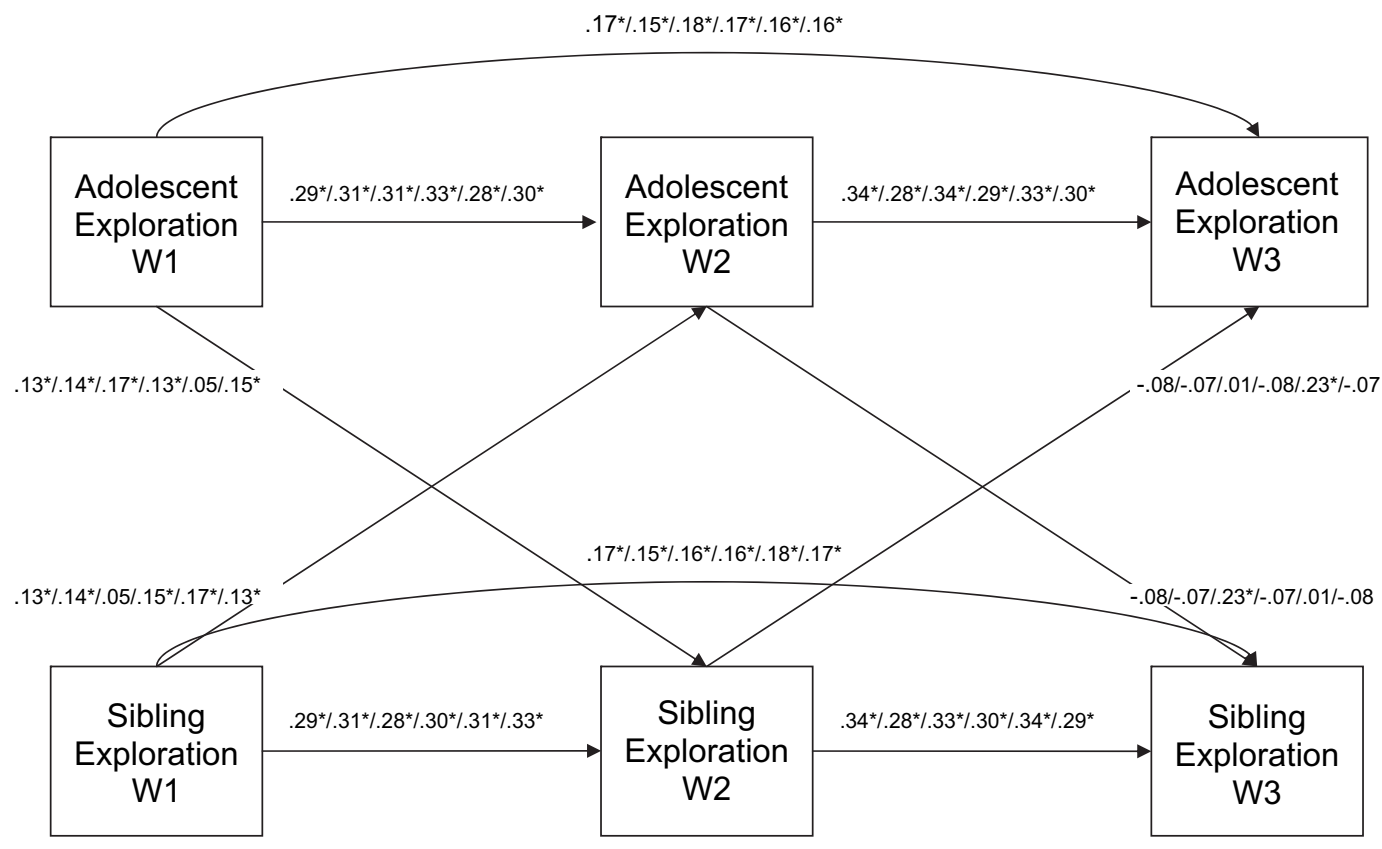

Fig. 2. Path-analytic model of sibling related exploration. Note. Standardized correlations of significant paths of the sibling groups are printed. The first two correlations are that of respectively respondents with a same-sex or with a opposite-sex sibling close in age, the third and fourth that of respectively earlier-born respondents with a same-sex or opposite-sex sibling, and the last two correlations that of respectively later-born respondents with a same-sex or opposite-sex sibling. Since paths of adolescents and siblings belonging to the same sibling type are set equal (for instance, a same-sex earlier-born sibling and a same-sex earlier-born respondent), coefficients of those adolescents are the same. For example, the third coefficient of adolescent exploration w2 $\rightarrow$ sibling exploration w3 is the same as the fifth coefficient of sibling exploration w2 $\rightarrow$ adolescent exploration w3. ${ }^{*} p<0.05$.

This is probably because changes in identity may not be evident for siblings right away. It might take some time before new levels of exploration or commitment are displayed by adolescents or emerging adults and therefore become visible for the outside world such as siblings.

Focusing on the different sibling groups, results confirmed the expectation that sibling's identity particularly affected later-born respondents of the same sex. Both commitment and exploration of these respondents were influenced by their siblings' identity. This finding was in line with our hypotheses, and parallels with previous research on identification processes among same-sex and opposite-sex siblings (Benin \& Johnson, 1984). In contrast, in the other birth-order groups, regardless of sex, only exploration was affected by siblings' identity. This finding could indicate that older, same-sex siblings are especially important for the identity development of their later-born counterparts. This is probably because earlier-born siblings tend to have more power and a higher status than later-borns (Furman \& Buhrmester, 1985). Later-born siblings see their older sibling as competent, and therefore worthy for imitation (Bard \& Rodgers, 2003). Imitation may be especially pronounced when younger individuals admire their earlier-born siblings (Whiteman et al., 2007).

In terms of gender constellation, individuals with a same-sex sibling displayed higher levels of commitment and exploration than individuals with an opposite-sex sibling. Though we expected no differences between these groups, one explanation may be that same-sex siblings commonly have a higher relationship quality than do opposite-sex siblings (Furman \& Buhrmester, 1985), and that sibling relationship quality is positively related to identity development (Deković \& Buist, 2005).

In contrast to our hypotheses, the current study did not find support for differentiation processes in identity formation among siblings. Although prior studies have found evidence for a differentiation process between siblings for other aspects of adolescents' and emerging adults' development, such as antisocial behavior and autonomy (Feinberg \& Hetherington, 2000; Schachter et al., 1978), this does not seem to be the case for identity formation. Presumably, differentiation applies not so much to the process of identity formation, but rather to the content. In other words, siblings' levels of commitment might be unrelated, but they could also be committed to different things, which can indicate differentiation. This could be the case when, for instance, one sibling is doing a social study while the other is more focused upon economics. The fact that adolescents and emerging adults want to distinguish themselves might then be reflected in a different content of identity, not in different levels of commitment or exploration. Further, although we expected differentiation processes especially among earlier-born people or people with a sibling close in age, these types of respondents might be less sensitive for sibling influences, in the first place. For example, Whiteman and Christiansen (2008) showed that two-thirds of second-borns in their sample were influenced by their sibling in various domains of development, such as depression, risky behavior, and peer competence. In contrast, behavioral patterns of first-borns were influenced by their younger sibling in less than half of the cases. 
In summary, this study supports the existence of sibling identification process, but does not truly support the process of differentiation in identity formation. With regard to levels of commitment and exploration, it seems that siblings do not differentiate from one another, but instead only identify with each other. In answer to our research question regarding different effects for commitment versus exploration, we found that the influences of siblings' identity on respondents' own identity changes occur to a greater extent with regard to exploration than to commitment. This confirms our hypothesis that siblings identify more with respect to visible behavior than to intrinsic behavior, which is in line with previous research (e.g., Bard \& Rodgers, 2003; Rodgers et al., 1992).

\section{Strengths, limitations, and future directions}

The longitudinal measurement of identity processes is the primary strength of this study. By analyzing identity longitudinally, and thereby controlling for stability of commitment and exploration and correlations per wave, we can draw conclusions in terms of sibling influence upon changes in respondents' identity. Another strength is our assessment of identity in both siblings, which offers the opportunity to examine conditions under which sibling influences upon identity formation occur.

Our study was also limited in a number of ways, however. First, we only included one sibling per respondent, and information about the total number of siblings was not available. This ignores the fact that some individuals may have both younger and older sibling, or additional older/younger siblings. It may be true that another sibling influences the adolescent or emerging adult to a much greater extent. Future research could consider all siblings in indviduals' families, in order to more extensively examine the nature of sibling influences upon identity formation. Explicitly examining first-borns instead of earlier-borns, more generally, would additionally allow for a more direct test of the hypothesis about first-borns being more mature in identity formation.

Although the general pattern of findings was quite consistent, effects were not found consistently across measurement waves. More research is needed, both to replicate the findings and to examine the periods in which siblings are most influential upon identity development. The current study also did not consider the siblings' exact age differences. Greater age disparity offers younger siblings more time to observe their older brothers' or sisters' mature behaviors (French, 1984), however, and generally increases younger individuals' admiration of their older siblings (Bard \& Rodgers, 2003). This might lead to a higher probability that later-born siblings will imitate the earlier-born siblings' behaviors. Related to this issue, and depending on the period of life in question, siblings may have a dissimilar influence on identity development. During early adolescence, for example, sibling influence might be different from that during emerging adulthood.

This study is also limited in terms of not taking sibling relationship quality into account. Prior studies have found that sibling influences are higher within the context of high relationship quality (Brody, 1998; Rowe \& Gully, 1992), particularly in terms of modeling processes (Whiteman et al., 2007). Though sibling relationship quality is related to identity (Deković \& Buist, 2005), the question is whether it is also related to the influence of siblings' identity. Future research could address this possible interaction effect of sibling relationship quality.

\section{Conclusion}

Even though more research is needed to examine whether and how all siblings influence identity development, the present study demonstrates that the level of commitment and exploration partly depends on influences such as birth order and sibling gender configuration. Especially for people with an earlier-born, same-sex sibling, identity depends also on the sibling's levels of commitment and exploration. Identification processes, in particular, seem to play a role in sibling influences upon identity development.

\section{References}

Arnett, J. J. (2000). Emerging adulthood: a theory of development from the late teens through the twenties. American Psychologist, 55, 469-480.

Adler, A. (1928). Characteristics of the first, second, and third child. Children, 3, 14-52.

Bank, S., \& Kahn, M. D. (1976). Sisterhood-brotherhood is powerful: sibling sub- systems and family therapy. In S. Chess, \& A. Thomas (Eds.), Annual progress in child psychiatry and child development (pp. 493-519). New York: Bruner/Mazel.

Bard, D. E., \& Rodgers, J. L. (2003). Sibling influence on smoking behavior: a within- family look at explanations for a birth-order effect. Journal of Applied Social Psychology, 33, 1773-1795.

Bedford, V., \& Volling, B. (2004). A dynamic ecological systems perspective on emotion regulation development within the sibling relationship. In F. Lang, \& K. Fingerman (Eds.), Growing together: Personal relationship across the lifespan (pp. 76-101). New York: Cambridge University Press.

Benin, M. H., \& Johnson, D. R. (1984). Sibling similarities in educational attainment: a comparison of like-sex and cross-sex sibling pairs. Sociology of Education, 57, 11-21.

Bosma, H. (1985). Identity development in adolescence. Unpublished doctoral dissertation. The Netherlands: University of Groningen.

Bosma, H. A., \& Kunnen, S. E. (2001). Determinants and mechanisms in ego identity development: a review and synthesis. Developmental Review, 21, 39-66.

Branje, S. J., Van Lieshout, C. F., Van Aken, M. A., \& Haselager, G. J. (2004). Perceived support in sibling relationships and adolescent adjustment. Journal of Child Psychology and Psychiatry, 45, 1385-1396.

Brody, G. H. (1998). Sibling relationship quality: its causes and consequences. Annual Review of Psychology, 49, 1-24.

Buhrmester, D., \& Furman, W. (1990). Perceptions of sibling relationships during middle childhood and adolescence. Child Development, 61, $1387-1398$.

Crocetti, E., Rubini, M., \& Meeus, W. (2008). Capturing the dynamics of identity formation in various ethnic groups: development and validation of a threedimensional model. Journal of Adolescence, 31, 207-222.

Deković, M., \& Buist, K. L. (2005). Multiple perspectives within the family: family relationship patterns. Journal of Family Issues, 26, 467-490. 
Erikson, E. H. (1968). Identity, youth and crisis. New York: Norton.

Feinberg, M. E., \& Hetherington, E. M. (2000). Sibling differentiation in adolescence: implications for behavioral genetic theory. Child Development, 71, $1512-1524$.

Feinberg, M. E., McHale, S. M., Crouter, A. C., \& Cumsille, P. (2003). Sibling differentiation: sibling and parent relationship trajectories in adolescence. Child Development, 74, 1261-1274.

French, D. C. (1984). Children's knowledge of the social functions of younger, older, and same-age peers. Developmental Psychology, 55, 1429-1433.

Furman, W., \& Buhrmester, D. (1985). Children's perceptions of the qualities of sibling relationships. Child Development, 56, $448-461$.

Grotevant, H. D., \& Cooper, C. R. (1985). Patterns of interaction in family relationships and the development of identity exploration in adolescence. Child Development, 56, 415-428.

't Hart, H. (1992). Opzet en uitvoering van het WIL-panel 1 en 2 [Design and data-collection of The Utrecht Study of Adolescent Development 1 and 2]. Unpublished manuscript, Utrecht University.

Kalakoski, V., \& Nurmi, J.-E. (1998). Identity and educational transitions: age differences in adolescent exploration and commitment related to education, occupation, and family. Journal of Research on Adolescence, 8, 29--47.

Kerpelman, J. L., Pittman, J. F., \& Lamke, L. K. (1997). Toward a microprocess perspective on adolescent identity development: an identity control theory. Journal of Adolescent Research, 12, 325-346.

Kline, R. B. (2005). Principles and practice of structural equation modeling (2nd ed.). New York: The Guilford Press.

Luyckx, K., Goossens, L., Soenens, B., \& Beyers, W. (2006). Unpacking commitment and exploration: preliminary validation of an integrative model of late adolescent identity formation. Journal of Adolescence, 29, 361-378.

Marcia, J. E. (1966). Development and validation of ego-identity status. Journal of Personality and Social Psychology, 3, 551-558.

McHale, S. M., Updegraff, K. A., Helms-Erikson, H., \& Crouter, A. C. (2001). Sibling influences on gender development in middle childhood and early adolescence: a longitudinal study. Developmental Psychology, 37, 115-125.

Meeus, W. (1996). Studies on identity development in adolescence: an overview of research and some new data. Journal of Youth and Adolescence, 25, 569-598.

Meeus, W., Iedema, J., Helsen, M., \& Vollebergh, W. (1999). Patterns of adolescent identity development: review of literature and longitudinal analysis. Developmental Review, 19, 419-461.

Meeus, W., Iedema, J., \& Maassen, G. H. (2002). Commitment and exploration as mechanisms of identity formation. Psychological Report, 90, 771-785.

Meeus, W., Oosterwegel, A., \& Vollebergh, W. (2002). Parental and peer attachment and identity development in adolescence. Journal of Adolescence, 25, 93-106.

Meeus, W., Van de Schoot, R., Keijsers, L., Schwartz, S. J., \& Branje, S. (2010). On the progression and stability of adolescent identity formation. A five-wave longitudinal study in early-to-middle and middle-to-late adolescence. Child Development, 81.

Meeus, W., \& 't Hart, H. (Eds.). (1993). Jongeren in Nederland. Een nationaal survey naar ontwikkeling in de adolescentie en naar intergenerationele overdracht. [Young people in the Netherlands. A national survey into adolescent development and intergenerational transmission]. Amersfoort: Academische Uitgeverij.

Muthén, L. K., \& Muthén, B. O. (1998). Mplus user's guide (4th ed.). Los Angeles, CA: Muthén \& Muthén.

Plotkin, H. (1999). Evolution in the family. Biology and Philosophy, 14, 451-458.

Rodgers, J. L., Rowe, D. C., \& Harris, D. F. (1992). Sibling differences in adolescent sexual behavior: inferring process models from family composition patterns. Journal of Marriage and the Family, 54, 142-152.

Rowe, D. C., \& Gully, B. L. (1992). Sibling effects on substance abuse and delinquency. Criminology, 30, 217-234.

Satorra, A., \& Bentler, P. M. (2001). A scaled difference chi-square test statistic for moment structure analysis. Psychometrika, 66, 507-514.

Schachter, F. F., Gilutz, G., Shore, E., \& Adler, M. (1978). Sibling deidentification judged by mothers: cross-validation and developmental studies. Child Development, 49, 543-546.

Schultheiss, D. E. P., Palma, T. V., Predragovich, K. S., \& Glasscock, J. M. J. (2002). Relational influences on career paths: siblings in context. Journal of Counseling Psychology, 49, 9.

Sulloway, F. J. (1996). Born to rebel: Birth order, family dynamics, and creative lives. New York, NY: Pantheon Books.

Sulloway, F. J. (2001). Birth order, sibling competition, and human behavior. In H. R. Holcomb, III (Ed.), Conceptual challenges in evolutionary psychology: Innovative research strategies (pp. 39-83). Dordrecht, The Netherlands: Kluwer Academic.

Waterman, A. S. (1988). Identity status theory and Erikson's theory: commonalities and differences. Developmental Review, 8, 185-208.

Whiston, S. C., \& Keller, B. K. (2004). The influences of the family of origin on career development: a review and analysis. The Counseling Psychologist, 32 , 493-566.

Whiteman, S. D., \& Christiansen, A. (2008). Processes of sibling influence in adolescence: individual and family correlates. Family Relations, 57, 24-34.

Whiteman, S. D., McHale, S. M., \& Crouter, A. C. (2007). Competing processes of sibling influence: observational learning and sibling deidentification. Social Development, 16, 642-661. 